\title{
The cerato-mandibular ligament: a key functional trait for grazing in damselfishes (Pomacentridae)
}

\author{
Damien Olivier $^{1 *}$, Bruno Frédérich ${ }^{1}$, Milton Spanopoulos-Zarco ${ }^{2}$, Eduardo F Balart ${ }^{3}$ and Eric Parmentier ${ }^{1}$
}

\begin{abstract}
Introduction: The success of a taxonomic group can be promoted by a key character that allows the group to interact with its environment in a different way and to potentially occupy new niches. The Pomacentridae possess a synapomorphic trait, the cerato-mandibular (c-md) ligament, which joins the hyoid bar to the inner part of the lower jaw. It has previously been shown that this ligament is a key trait in communication in damselfishes because it enables them to slam the oral jaws shut causing teeth collision and sound production. This specific behavior of mouth closing could, however, also be used for other tasks, such as feeding. Many territorial damselfishes are referred to as farmers, due to their ability to manage algal crops on which they feed. This study hypothesizes that the c-md ligament provides an advantage for grazing filamentous algae, and should thus be considered a key trait for farming behavior.

Results: The kinematic patterns associated with sound production and biting filamentous algae or attached animal prey are all based on the same mechanism and are associated with a slam of the oral jaws. We observed that transection of the c-md ligaments makes the fish unable to perform such actions. We also counted biting rates on filamentous algae in fish with and without the c-md ligament and observed a drop of more than $80 \%$ in the latter.

Conclusion: This study shows that the c-md ligament is a key trait both for sound production and for grazing activities in damselfishes. The buccal jaw slam enables the fish to perform accurate strikes on small filamentous algae. This kind of bite probably plays a major role in farming activity and allows grazing damselfishes to occupy distinct niches, possibly increasing their competitive evolutionary success.
\end{abstract}

Keywords: Biomechanics, Evolution, Farming, Functional morphology

\section{Introduction}

The evolutionary success of a taxonomic group can sometimes be explained by at least one key character that enables the taxon to interact with its environment in a different way, and allows it to be more competitive [1]. Such a character is commonly labelled a "key innovation". Although different definitions of key innovations have been proposed [1-7], all of them share the basic idea that some attributes of the organism have been important over evolutionary time [8] and that the key innovation allows the utilization of resources in ways not previously possible $[9,10]$. The pharyngeal jaw in cichlids [11], the intramandibular joint in squamipinnes such as pomacanthids and acanthurids [12-16], the

\footnotetext{
*Correspondence: dolivier@ulg.ac.be

${ }^{1}$ Laboratoire de Morphologie Fonctionnelle et Evolutive, AFFISH Research Center, Institut de Chimie (B6C) Université de Liège, B-4000 Liège, Belgium Full list of author information is available at the end of the article
}

"beak-like" jaws in parrotfishes [17], the toepads of geckos $[10,18]$, the presence of molars with a hypocone in mammals [19] are all classic examples of key innovations in vertebrates.

The Pomacentridae (damselfishes) represent one of the most successful radiations of coral and rocky reef fishes [20,21]. Many of them are territorial, ubiquitous grazers and are considered as a keystone group for the diversity of benthic communities that include filamentous and corticated palatable algal and small invertebrates [22-25]. These species are often called farmers since they manage algal crops that they feed on in their territory [24-28]. The farming behavior involves the defense of a patch of territory from which roving grazers, such as acanthurids, scarids or siganids, are chased; cleaning up of debris; and weeding out undesirable algae [29,30]. Sounds from damselfishes are well-known and occur during aggressive territory defense and/or courtships 
[31-34]. In the zooplanktivorous Amphiprion clarkii, aggressive sounds result from teeth collision induced by a buccal jaw slam [35]. This rapid mouth closing movement is due to the cerato-mandibular ligament (c-md) joining the lateral side of the hyoid bar to the medial side of the lower jaw (Figure 1), a synapomorphic trait of the Pomacentridae [36]. The mechanism of the c-md ligament was determined by manipulations of fresh euthanized fish, and high-speed videos using X-ray and visible light sources. When the neurocranium and the hyoid apparatus are held at rest, the c-md ligament is loose and cannot transmit force to the lower jaw (Figure 2A). Pulling along the working-line of the epaxial muscle rotates clockwise the neurocranium (in left lateral view). This movement, via a four-bar linkage (see [37] for details), causes the hyoid bar to rotate counterclockwise which induces the mouth opening [37] and gradually moves away the insertion points of the c-md ligament until it is fully strained (Figure 2B). In this state, additional elevation of the neurocranium and/or depression of the hyoid bar make(s) the taut ligament close the mouth by inducing rotation of the lower jaw around its quadrate articulation (Figure 2C). The same mechanism of mouth opening and closing can be obtained by pulling along the working-line of the sternohyoideus muscle, but there is no neurocranium elevation in this case.

The cerato-mandibular ligament is considered a key character in communication in pomacentrids. Nevertheless, its involvement in other tasks remains unexplored. As the c-md ligament is involved in production of a bite motor pattern, we may expect that a scraping species that feeds on filamentous algae could also use this particular mechanism of mouth closure to feed. We thus hypothesize that the same mechanism might be used in two distinct behaviors: feeding and sound production. Studying the kinematics associated with prey capture allows for a better understanding of the behavioral performances associated with feeding ecology. For example, chaetodons are known to possess a wide range of biomechanical specializations associated with several trophic guilds [38,39]. The jaw kinematics of pomacanthids have been associated with their specialization on cryptobenthic resources [12]. Similarly, an understanding of the unexplored prey-capture kinematics in pomacentrids could shed light on their feeding ecology.

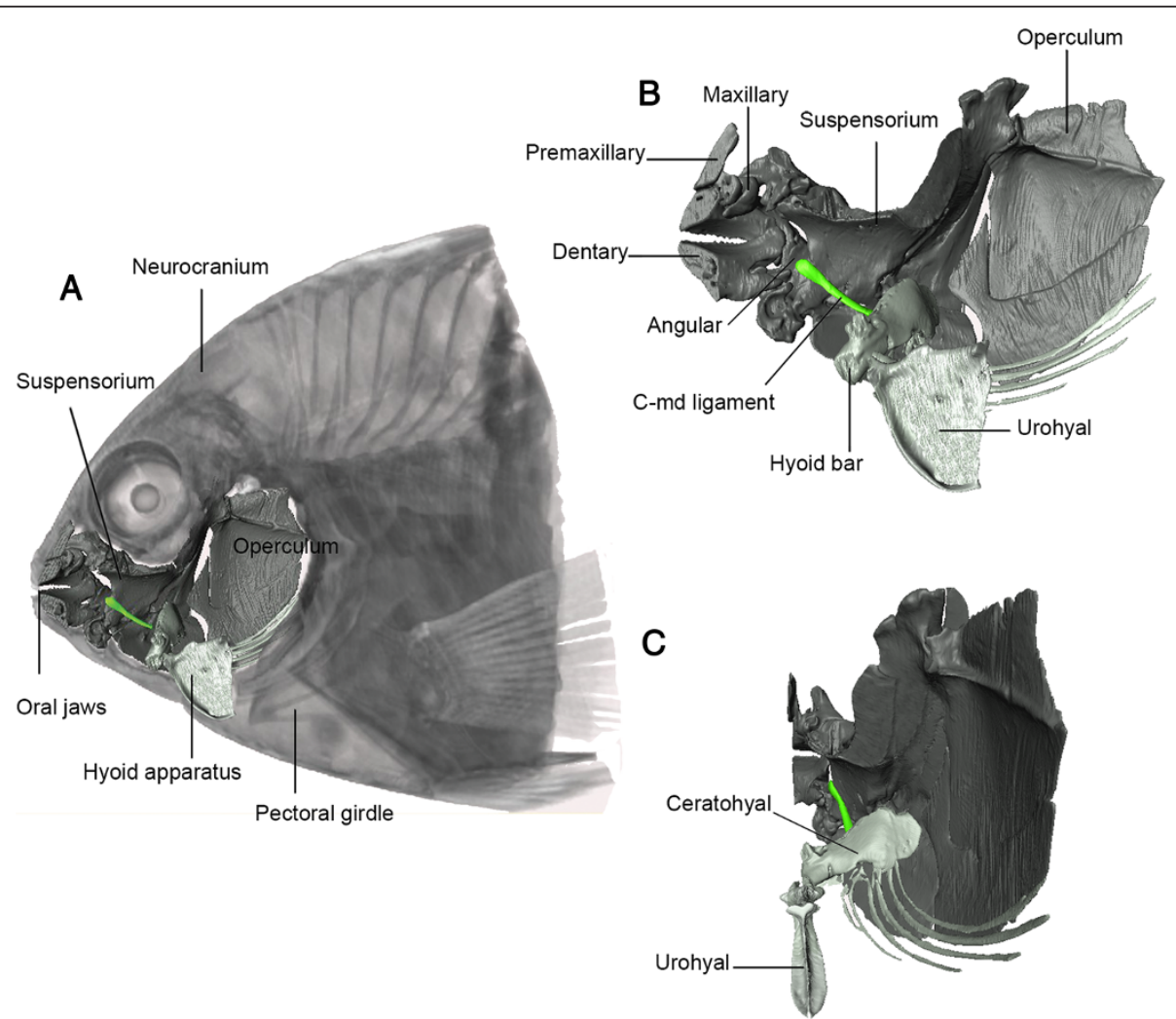

Figure 1 Representation of the cerato-mandibular (c-md) ligament in Pomacentridae. A) Left lateral view of Stegastes rectifraenum skull and pectoral girdle. The left oral jaws, suspensorium, opercles and hyoid bar have been removed allowing view of the right part of the hyoid apparatus in the buccal cavity. The opercles, the suspensorium, the oral jaws, the hyoid apparatus and the c-md ligament (in green) of the right side are 3-D reconstructed. B) and C) Zoom on the 3-D reconstruction from a lateral and transverse view. 


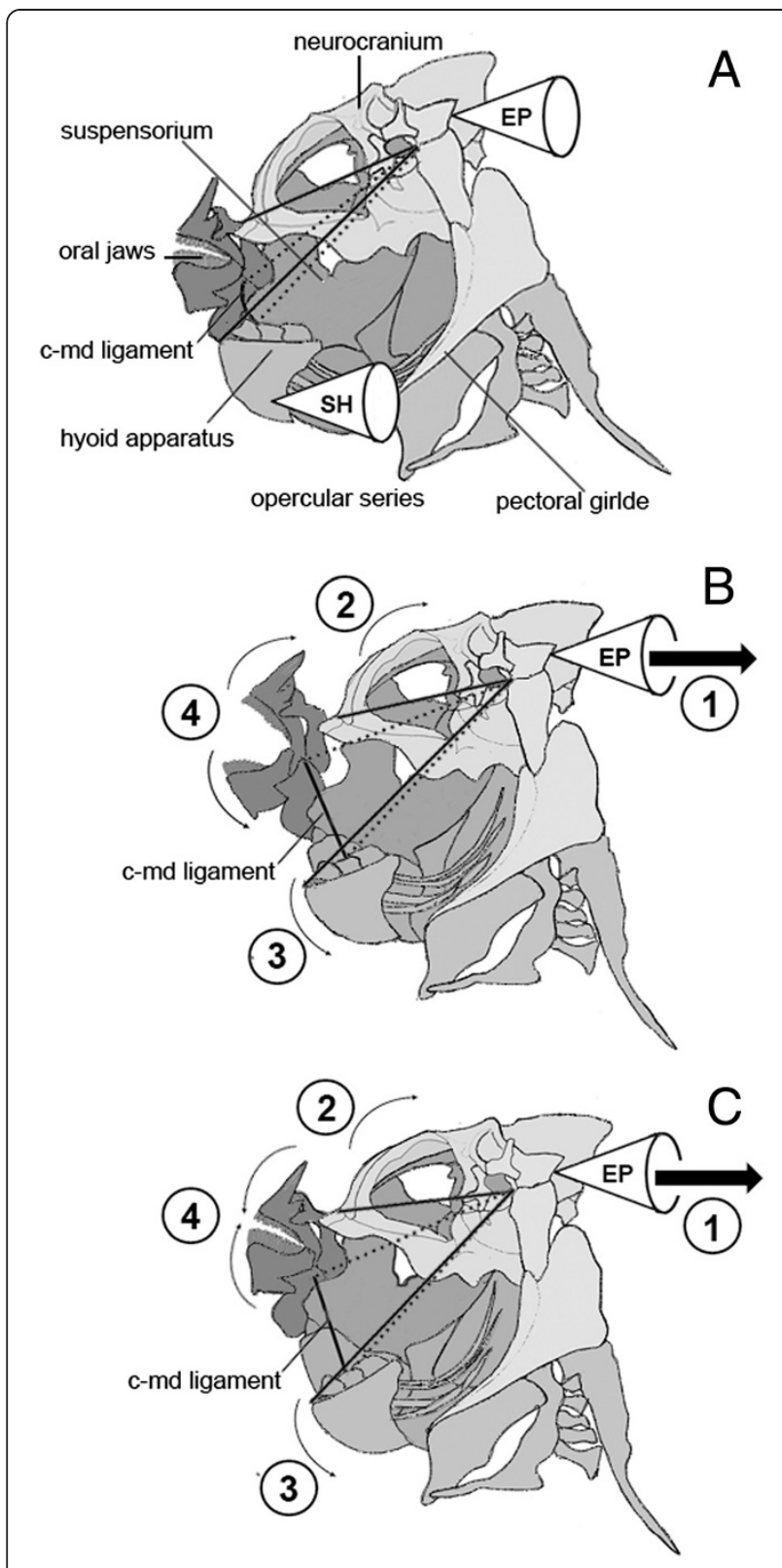

Figure 2 Illustration of the cerato-mandibular ligament mechanism. As for the figure 1, the left oral jaws, suspensorium, opercles and hyoid bar have been removed to allow a view of right part of the hyoid apparatus in the buccal cavity. White cones indicate two muscle groups: epaxial muscles (EP) and sternohyoideus muscle (SH). In A. no movements occurs and the c-md ligament is loose. In B. Pulling on the epaxial muscle (1) induces a rotation of the neurocranium (2) provoking a rotation of the hyoid apparatus (3) which results in mouth opening (4) and in the straining of the c-md ligament. In $\mathbf{C}$. additional pulling on the epaxial muscles (1) induces higher rotations of neurocranium and hyoid apparatus (2 and 3) which results, as the c-md ligament is now fully strained, in mouth closing (4). The same phenomenon of both mouthopening and closing can be obtained by pulling along the working-line of the sternohyoideus muscle (represented in A) but there is no neurocranium elevation in this case. The angle measuring the relative movement of the two insertion points of the c-md ligament is represented by dotted lines. The angle measuring the relative movement between the neurocranium and the hyoid apparatus is represented by full lines.
Stegastes species appear to be a good model to investigate this duality in function. Fish from this genus hold permanent territories for the culture of filamentous algae (see [21]) and this taxon is particularly well known to include active sound producing species that use sound in many different behavioral contexts such as courtship, territorial defense (against conspecifics and heterospecifics) and chases [40-44].

Here, we investigated the role of the c-md ligament in the feeding behavior of the Cortez damselfish Stegastes rectifraenum, an endemic species of the eastern Pacific living on rocky or coral reefs and reported to be a farmer species [45]. Sound production was also described in this study since it had not been published previously. We found that oral jaw slams because of the c-md ligament, and that this behavior is necessary for both sound production and the grazing of filamentous algae in S. rectifraenum. Beyond its functional role, we illustrate that the mouth-closing mechanism involving the c-md ligament (1) may mitigate the functional tradeoff of force and velocity transmission to the lower jaw and (2) might be the key trait for the farming behavior in pomacentrids.

\section{Methods}

Experimental and animal care protocols followed all relevant international guidelines and were approved by the ethics commission of the University of Liège (protocol no.113).

\section{Specimens and husbandry}

Twenty-two adult individuals (Standard Length $\approx 10 \mathrm{~cm}$ ) were caught at Punta Diablo $\left(24^{\circ} \mathrm{N}, 110^{\circ} \mathrm{O}\right)$ near the city of La Paz in the Gulf of California (México). These fish were then held in the Centro de Investigaciones Biológicas del Noroeste (CIBNOR) in a plastic common flowthrough $750 \mathrm{l}$ tank with shelters (PVC tubes) at ambient temperature $\left(24\right.$ to $26^{\circ} \mathrm{C}$ ), and subject to natural photoperiod (14 L:10D). The 22 species were divided in four groups for the different experiments: three individuals were used for the kinematic analysis related to feeding behaviors, four were used for the kinematic analysis of sound production, three were used for electromyographic study and twelve for biting rate experiments. One of these individuals was used for 3-D reconstruction.

\section{3-D reconstruction of the head morphology}

To illustrate the insertions and shape of the c-md ligament, one individual (SL: $9.7 \mathrm{~cm}$ ) was scanned at the National Museum of Natural History in Paris with a $\mu C T$-scan (v|tome|x 240 L, GE Sensing \& Inspection Technologies Phoenix X|ray). Prior to being scanned, the specimen was submerged in a 5\% phosphomolybdic acid solution for ten days to improve contrast between 
the different tissues. The imaging system was set at $250 \mathrm{kV}$ and the specimen was scanned at isotropic resolutions of $32 \mu \mathrm{m}$. Volume and surface rendering was performed with AMIRA 5.4.0 (VSG, FEI company).

\section{Sounds recordings}

Recordings were conducted on fish (sets of 4 to 10) kept in the plastic communal tank until their use in other experiments. All electrical devices were switched off during the recordings. The hydrophone (HTI-96-Min; sensitivity: $-164.4 \mathrm{~dB}$ re: $1 \mathrm{~V} / \mu \mathrm{Pa}$; flat frequency response range between $2 \mathrm{~Hz}$ and $30 \mathrm{kHz}$ ) was positioned in the middle of the tank and connected to a TASCAM DR-05 portable digital recorder (recording bandwith: $20 \mathrm{~Hz}$ to $20 \mathrm{kHz} \pm 1.0 \mathrm{~dB})$. Sounds were digitized at $44.1 \mathrm{kHz}(16$ bit resolution) and analysed with the Avisoft-SASLab Pro version 5.2.07 software. A low-pass filter of $2 \mathrm{kHz}$ was applied to all recordings. The duration (in milliseconds) of pulses was measured from the oscillograms and dominant frequency (i.e. frequency conveying the most acoustical energy) was obtained from power spectra (filter bandwith $300 \mathrm{~Hz}$, FFT size point 256, time overlap $96.87 \%$ and a flat top window). The behavior accompanying sound production was recorded with a video camera GoPro (HD Hero3 White, Woodman Labs, USA; 29 frames per second).

\section{High-speed movies recordings}

Three of the 22 fish were placed in separate flowthrough $140 \mathrm{l}$ aquaria for kinematic analysis of feeding behavior. Each tank had a shelter in front of which was placed a corridor of $20 \mathrm{~cm}$ in length, $50 \mathrm{~cm}$ in height and $10 \mathrm{~cm}$ of width. The fish were trained to leave their shelter to gain access to food placed at the extremity of the corridor. Two kinds of food were given: filamentous algae on small rock (natural diet) and pieces of shrimp fixed to tweezers. A high-speed video camera (Model NX4-S1, IDT, Tallahassee, USA; 640x456 pixels) was used to record feeding behaviors at 500 frames per second (fps). Four kinds of feeding events were studied in three individuals. Grazing of filamentous algae $(F A)$ and biting fixed pieces of food (shrimps) (FPF) were first analyzed. The same behaviors were studied anew in the same individuals after the surgical transection of the c-md ligaments $\left(F A^{*}\right.$ and $\left.F P F^{*}\right)$. For the c-md ligaments transection, the fish were anesthetized with $200 \mathrm{ppm}$ of tricaine methanesulfonate (MS-222). The individuals were then operated using a dissecting microscope by inserting a thin blade between the lower jaw and the hyoid bar to cut the c-md ligament in its middle part. This operation was performed on both right and left sides. Disinfectant (Ingredient Propolis Alcohol) was then injected in the buccal cavity. Because previous examinations have shown that an intact c-md ligament closes the mouth when the fish is manipulated only by pulling backward on the epaxial or the sternohyoideus muscles, it was possible to check the success of the surgery with these manipulations. The fish that were successfully operated were then placed in a recovery bucket with oxygenated seawater. Once the fish started to move again, they were placed in their individual tank and their recovery was monitored for $30 \mathrm{~min}$. The animals were then left at rest for a period of $24 \mathrm{~h}$. After this time individuals were presented with food and their behavior was recorded with the high-speed video camera. At the end of experiment, all fish were euthanized and dissected to check the section of the c-md ligaments and to ensure that other structures were not damaged. Five films were recorded for each event and for each fish $(n=3)$. We analyzed only video sequences with fish in lateral view and when all points of interest were clearly visible. To study the kinematic pattern associated with sound production, a fish was isolated in a corridor as long as the entire tank (in the same aquarium as those used for feeding behavior). A shelter was placed in the corridor, allowing the fish to establish its territory. After two days, a grid was placed in the corridor in order to isolate both the fish and its shelter. A second fish was then introduced into the second part of the corridor to provoke aggressive behavior from the resident. Movements associated with sound production were then video recorded. The grid was used to prevent fighting among the fish.

\section{Analysis of the films}

The goal of the current study was to compare the kinematic patterns used in different behaviors. The use of regular (from an external view) high-speed video allowed us to obtain more data and to perform quantitative studies. Although with this method we could not directly measure the movement between the c-md insertion points (angle in dotted lines on Figure 2), we were able to monitor movements of the structures causing the movement of these elements i.e. the neurocranium and the hyoid apparatus. We decided to use the angle measuring the relative movement between the anterior parts of the neurocranium and the hyoid apparatus (angle in full lines on Figure 2) as a proxy for the relative movement between the c-md insertion points.

Each image of the videos was digitized with the software Motion Studio 64. Five landmarks were chosen (Figure 3) to quantify cranial movements. 1) the hyomandibular articulation on the neurocranium; 2) the anterior part of the neurocranium; 3) protrusion of the urohyal (representative of the hyoid apparatus); 4) the anterior part of the preopercular horizontal limb and 5) the anterior tip of the dentary. The hyomandibular articulation (landmark 1) is close to the joint between the post-temporal and supracleithrum bones of the pectoral girdle, which is the pivot point of the neurocranium 


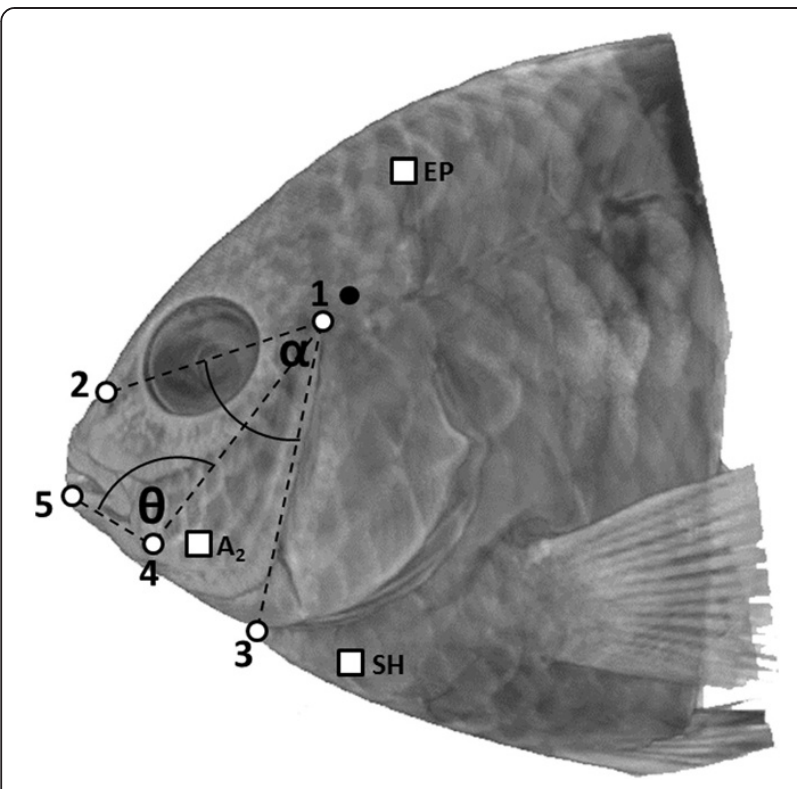

Figure 3 Illustration of the landmarks to measure kinematic variables and electrodes positions for electromyography study. 1: Dorsal suspensorium articulation; 2: Neurocranium; 3: Protrusion of the hyoid apparatus; 4: Anterior part of the horizontal limb of the preopercular; 5: Dentary of the lower jaw. The angle a measures the relative distance between the neurocranium and the protrusion of the hyoid apparatus, the angle $\theta$ measures the lower jaw rotation, the black landmark indicates the articulation between neurocranium and pectoral girdle. The white square indicate where the electrodes were placed for the electromyography study (EP: epaxial muscle; SH: sternohyoideus muscle and $\mathrm{AM}_{2}$ : one of the main subdivisions of the adductor mandibulae muscle).

(Figure 3). The landmarks allowed for the measurement of eight variables including maximum angles $\left(^{\circ}\right)$, speed $\left({ }^{\circ} \mathrm{s}^{-1}\right)$, acceleration $\left({ }^{\circ} \mathrm{s}^{-2}\right)$ and timings $(\mathrm{ms})$, which were then used to describe each kinematic pattern. \#1) the maximum relative movement between the neurocranium and the hyoid apparatus (MRM), which was measured through the angle $\alpha$ (Figure 3 ); \#2) the maximal lower jaw depression, which was measured through angle $\theta$ (Figure 3$)$; \#3) the mean angular closing speed of the lower jaw; \#4) the maximum angular acceleration by which the neurocranium and the hyoid apparatus move away from one another; \#5) the time between the bite and the MRM; \#6) the synchronization between the hyoid apparatus and the lower jaw displacements, measured as the time between maximum acceleration of the hyoid apparatus movement (measured as a distance) and the maximum acceleration of the lower jaw elevation; \#7) the mouth closing duration and \#8) the mouth opening duration. Each analysis starts with the onset of mouth opening and finishes at the time of the seizure of food items or the teeth collision for sound production.

To reduce the dimensionality of the dataset and to determine the degree of correlation between kinematic variables, we performed a principal components analysis (PCA) using the underlying correlation matrix (Statistica, version 10). As the c-md ligament is not involved in the mouth opening phase, the variable "mouth opening duration" was not included in the PCA. The scores of the two main PCs were used to test the differences in the kinematic patterns among sound production and the various prey capture events. In addition, we were interested to know which variables were different. Only one variable (maximal lower jaw depression) did not violate the assumption for parametric analysis using the normality test in Statistica v.10. For this reason an ANOVA, followed by a Bonferroni post-hoc test, was used for this variable and a Kruskal-Wallis test followed by a multiple comparisons of mean ranks post-hoc test was applied for the others. Each strike has to be categorized according to our kinematic variables as similar (or not) to the motion performed during sound production. For this reason, we considered each video an independent data point.

\section{Bite rates}

Bite rates of individuals were compared before and after the c-md ligaments transection to assess the functional importance of the c-md ligament in the grazing filamentous algae. A flow-through $750 \mathrm{l}$ aquarium was divided into four parts, and one fish was placed in each compartment. Two days later and over a period of five days, rocks with filamentous algae were placed at three intervals of $30 \mathrm{~min}$ duration (09:00 am.; midday and 03:00 pm) in each compartment. The feeding periods were filmed with a GoPro camera and bite rates were counted during the last $15 \mathrm{~min}$ of each video. In order to allow the fish to acclimate to these feeding trials, biting rates were not counted the first day. To avoid exposing fish repeatedly to the same rocks, rocks were placed in different compartments for each feeding period. During the first set, the c-md ligament was present in all fish. At the end of the first set, two fish were anesthetized with 200 ppm of MS-222 and their c-md ligaments were cut following the same methodology used in highspeed video recording experiments. After a recovery period of three days, bite rates were counted for four days. At the end, fish without c-md ligaments were euthanized with an overdose of MS 222 (400 ppm) and dissected to check the success of the surgical operation and verify that no other structures had been damaged. Simultaneously, the ligament was cut in the two remaining individuals and two new (intact) individuals were placed in the empty compartments. The experiment lasted a total of five weeks and 10 fish were studied. This protocol allowed the comparison of the behavior of each fish with and without the ligament. Each week, intact fish were used in the experiment, 
allowing the detection of any abnormal bite rates which could be due to a lack of filamentous algae on rocks. New rocks were sampled each week at Punta Diablo and were stored in a similar tank to the one used for the experiment. Bite rates were counted in eight fish because the last two individuals were only used to check if intact fish kept feeding. At the end of the experiment, 24 sequences of 15 min were analyzed per fish, 12 with the c-md ligament and 12 without. A control group made of 2 additional individuals was also monitored. These individuals were anesthetized with the same dose of MSS$222(200 \mathrm{ppm})$ and then released in their compartment. Their bite rates were then counted for four days. As the assumptions for parametric analyses were not violated, an ANOVA analysis followed by a Bonferroni post-hoc test was performed on the bite rates of three groups.

\section{Electromyography}

The EMG experiments were performed in one of the tanks used for kinematic analysis. The new slam mechanism of mouth closure described in the clownfish Amphiprion clarkii [35] showed that the mouth can be mechanically closed without the use of the adductor mandibulae. This has, however, never been tested in vivo. Therefore, EMG recording electrodes were placed in two individuals of $S$. rectifraenum in the subdivision $\mathrm{A}_{2}$ of the adductor mandibulae muscle (Figure 3 ). This muscle originates from the crescentic zone of the preopercular, the quadrate and the symplectic and inserts on to the lateral face of the coronoid process of the dentary [46]. Using EMG, we aimed to check the activity of this muscle during sound production and feeding events. In a third individual, recording electrodes were also placed in the epaxial (EP) muscle, close to the neurocranium and in the sternohyoideus $(\mathrm{SH})$, joining the urohyal to the pectoral girdle (Figure 3). The activity of these two muscles was only recorded during sound production event. Bipolar recording electrodes were made from pairs of $0.05 \mathrm{~mm}$ Tefloncoated stainless steel wire (Science Products $\mathrm{GmBH}$, Hofheimer, Germany) in which the insulation at the tip (1 $\mathrm{mm}$ ) of each wire was removed, the wire was inserted into a 25 gauge hypodermic needle and the exposed tips were bent back into hooks. Fish were anesthetized with 200 ppm of MS-222 and ventilated with seawater mixed with anesthetic solution while the electrodes were implanted and the hypodermic needle tips were removed. A loop of surgical silk suture thread was inserted in the dorsal trunk musculature, tied and glued with cyanoacrylate around electrodes for strain relief to prevent dislodgement of the electrodes. Fish were revived by ventilation with fresh seawater and placed back in the aquarium after a recovery period of approximately $30 \mathrm{~min}$. Electromyographic recordings were amplified in a four-channel differential amplifier (High-Gain Differential Amplifier Model 1700,
A-M Systems, Inc., WA, USA) with $10000 \mathrm{X}$ gain and band-pass filtered between 100 and $5000 \mathrm{~Hz}$ with a $60 \mathrm{~Hz}$ notch filter. At the end of the experiment, the fish were euthanized and dissected to check if the electrodes had been placed in the correct muscles.

Sounds in pomacentrids are produced by a jaw slam that causes teeth collision [32,35,47]; for this reason the start of the sound corresponds to the bite. The sounds produced during fighting and during the biting of filamentous algae can be clearly recorded with a hydrophone. Although it is softened, the sound corresponding to the impact of the teeth can also be discerned during biting of fixed pieces of food. The amplifier and the tascam were connected to an external USB sound card (Creative model SB0270: Creative labs, Singapore) and muscles activity and sound were recorded at $44.1 \mathrm{kHz}$ in Adobe Audition 2.0 software (Adobe, San Jose, CA, USA). Electromyographic data and sound recordings were digitized at $10 \mathrm{kHz}$ with Adobe Audition 2.0 software and rectified in Excel (2007). Muscle activity duration and sound onset were measured by calculating time periods for which the rectified waveform was three times the average background noise level. The time zero of muscle activity was defined as the time of the bite (onset of sound).

\section{Results \\ Sound}

In a tank, $S$. rectifraenum calls (Figure 4A) were associated with shelter defense (see Additional file 1) or biting filamentous algae (see Additional file 2). Pulse durations were significantly longer when biting filamentous algae but no significant difference was found between dominant frequency of calls and bites (Table 1, Figure 4B).

\section{Kinematics}

\section{Kinematic patterns with intact c-md ligament}

The kinematic patterns related to biting fixed piece of food $(F P F)$, filamentous algae $(F A)$ and sound production $(S P)$ could be split into three main phases (Figure $5 \mathrm{~A}$ ). High-speed videos of the three behaviors ( $S P$ and biting on $F A$ or $F P F$ ) are available in supplementary data (see Additional file 3).

Phase 1 Phase 1 consisted only of the depression of the lower jaw (Figure 5A). The duration of this phase for $F A$ was approximately half that of FPF $(54 \pm 22 \mathrm{~ms}$ vs $86 \pm$ $28 \mathrm{~ms}$ ) but the general aspect of this phase was similar for both feeding behaviors i.e. fish swam towards the food and depressed their lower jaw continuously (13 \pm $5^{\circ}$ for $F A$ and $11 \pm 4^{\circ}$ for $F P F$ ) (Figure 5A). The kinematic pattern during sound production could be divided into two parts. First, the fish continuously lowered their mandible for $23 \pm 14 \mathrm{~ms}$ down to $10 \pm 7^{\circ}$. Second, the 

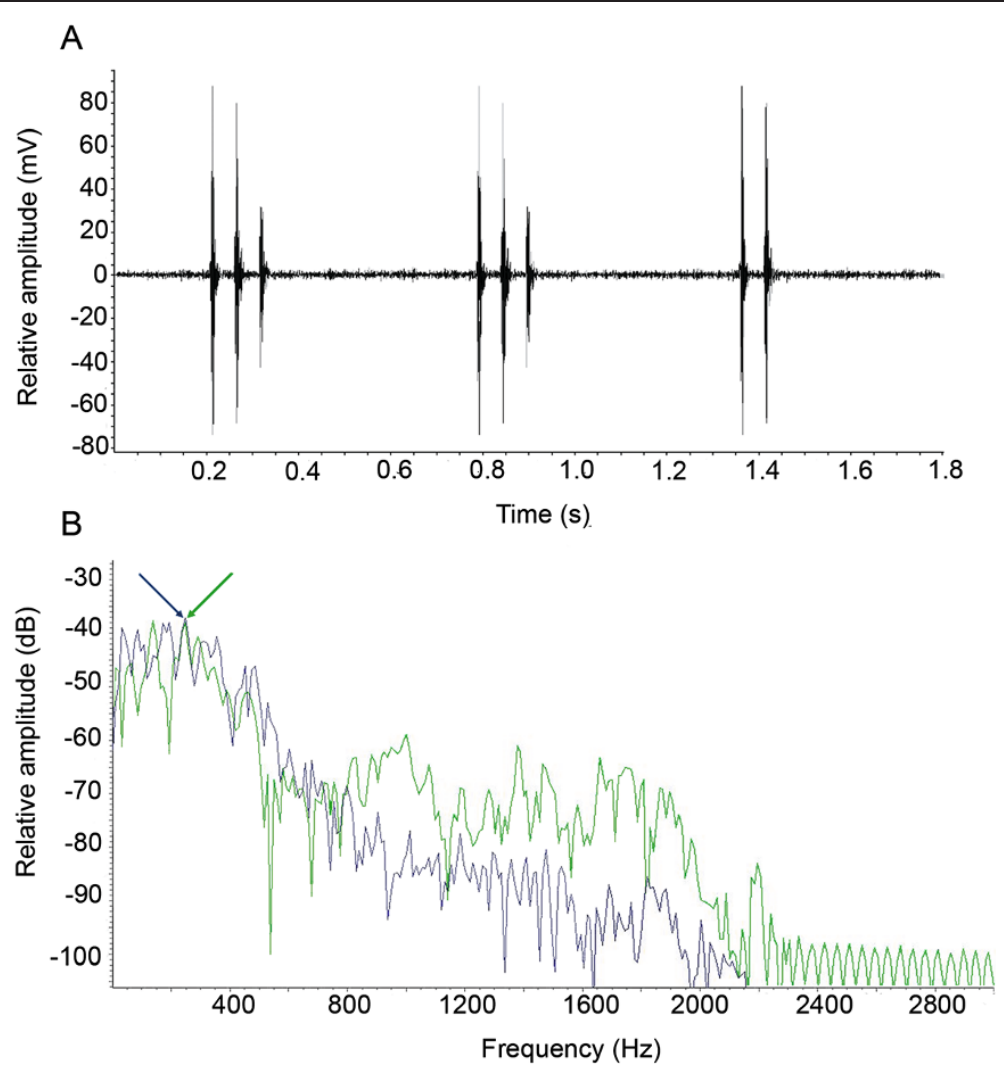

Figure 4 Waveform of sounds produced by Stegastes rectifraenum. A) Oscillogram of multiple-pulsed aggressive sounds. B) Power spectra of sound produced during agonistic behavior (green line) and grazing (blue line) showing the same dominant frequency (see arrows).

lower jaw stayed roughly at the same position until the end of phase 1 (depresses by $1 \pm 1^{\circ}$ during $24 \pm 16 \mathrm{~ms}$ ) (Figure 5A). Since no relative movement between the neurocranium and hyoid apparatus (RM) occurred during this phase, the c-md ligament stayed loose and could not transmit any tension to the lower jaw (Figure 5B).

Phase 2 For all behaviors, this phase was short $(9.3 \pm$ 3.5, $7.9 \pm 3.2$ and $8.9 \pm 5.2 \mathrm{~ms}$ for $F P F, F A$ and $S P$, respectively) and started with an increase in RM between neurocranium and hyoid apparatus (from 0 to 5.3, 3.6 and $7.5^{\circ}$ for $F P F, F A$ and $S P$, respectively) (Figure $5 \mathrm{~A}$ ). This motion moved the insertion points of the c-md ligament from their origin which progressively contributed to the ligament tightening (Figure $5 \mathrm{~B}$ ). During this phase the lower jaw kept lowering $\left(5.1 \pm 3.3^{\circ}, 4.6 \pm 1.7^{\circ}\right.$ and $3.4 \pm 5.4^{\circ}$ for $F A, F P F$ and $S P$, respectively).
Phase 3 In all behaviors, the mouth closed in a few ms (Table 2). A strong acceleration was observed in the RM between the neurocranium and hyoid apparatus, the RM reaching maximum amplitude (MRM) simultaneously with the bite (Figure 5A, Table 2). This movement allows the ligament to transmit a tension to the lower jaw which is forced to turn around its articulation and to close. As the RM increased rapidly, the mouth was closed in a slam. Maximal accelerations of the backward movement of the hyoid apparatus and lower jaw elevation were perfectly synchronized because the c-md ligament joins both structures (Table 2).

\section{Kinematic pattern with the c-md ligament ablated}

The ablation of the c-md ligament muted the fish: two operated fish placed in the same corridor still fighted but did not produce any sound. Moreover, no biting $F A$

Table 1 Comparison between sounds produced during agonistic behavior and filamentous algae biting

\begin{tabular}{llll}
\hline & Agonistic interaction (148) & Biting on filamentous algae (21) & U Mann-Whitney test \\
\hline Pulse duration (ms) & $24.66 \pm 9.70$ & $30.97 \pm 5.46$ & $Z=3.81 ; p<0.001$ \\
Dominant frequency $(\mathrm{Hz})$ & $307 \pm 106$ & $289 \pm 103$ & $Z=-1.69 ; p>0.05$ \\
\hline
\end{tabular}

Number of pulses is indicated in brackets. 


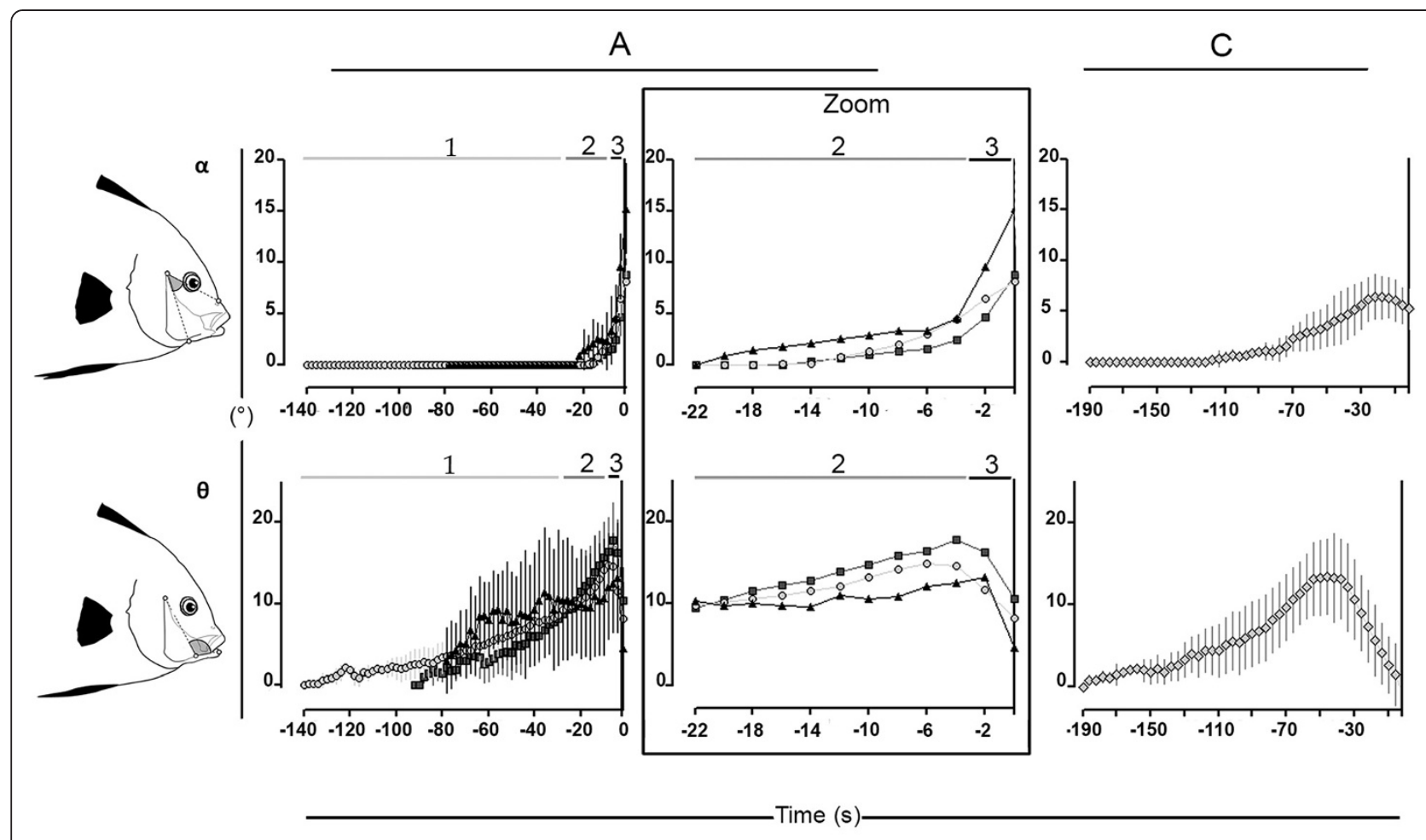

\section{B}
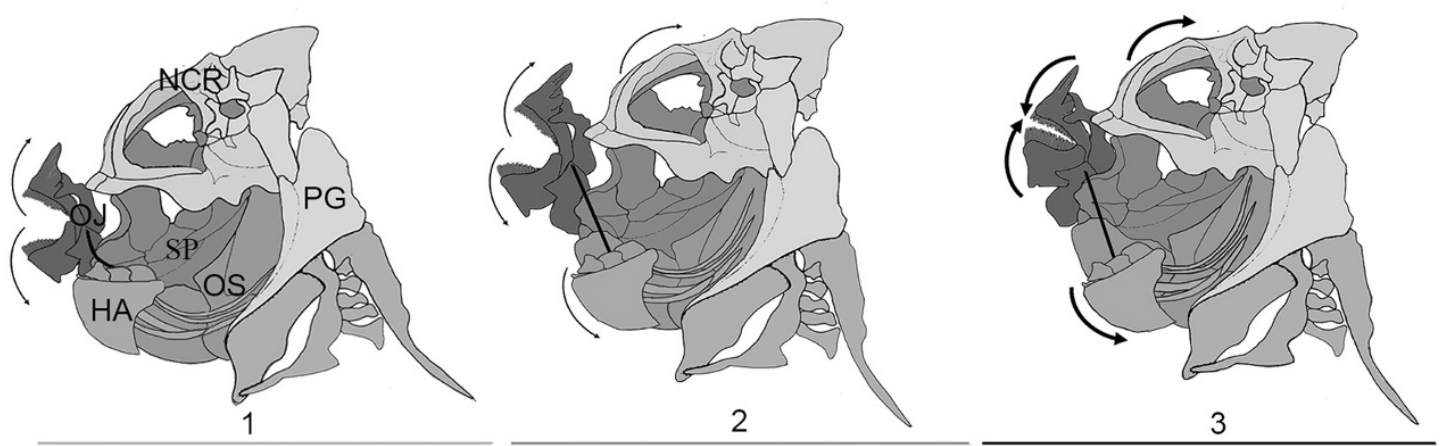

Figure 5 Kinematic analysis of sound production and feeding events in Stegastes rectifraenum. A) Representation of the mean kinematic patterns $( \pm$ SD) observed in sound production (black triangle), biting filamentous algae (dark grey square) and biting fixed pieces of food (light grey circle). The kinematic patterns end at the time of the bite. Figures 1,2 and 3 represent different phases: during phase 1, only the lower jaw is moving; phase 2 starts at the onset of the relative movement between the neurocranium and hyoid apparatus and finishes at the end of the aperture phase (maximum lower jaw depression); phase 3 represents the mouth closure period. A zoomed in portion is shown for the two latter phases, SD were withdrawn to allow a better visualization of the different patterns. B) Schematic illustration of the skull kinematics during the different phases (1, 2 and 3). The arrows indicate the movements observed during the corresponding phase. Bolder arrows indicate faster movements. The left cheek of the fish was withdrawn to allow an inner view in the buccal cavity. The nasal and the infraorbital series bones were also removed, to have a better view of the upper oral jaw. The protraction movement of the upper jaws is not illustrated. NCR: neurocranium; PG: pectoral girdle; OS: opercular series; SP: suspensorium; HA: Hyoid apparatus; OJ: oral jaws, the c-md ligament is in black. C) Representation of the mean kinematic pattern $( \pm S D)$ for biting fixed pieces of food while the c-md ligament is ablated. The kinematic pattern ends at the time of the bite.

events were observed. However the same surgery did not impede individuals to bite FPF. Consequently, we analyzed only the kinematic pattern associated with this behavior $\left(F P F^{*}\right)$.

As in $F P F$, the fish swam towards the food while the lower jaw depressed continuously. However, the neurocranium and hyoid apparatus were not abruptly moved away from one another, the maximum acceleration of their relative separation was six times slower than in FPF (Table 2). Both structures did not continue their movement until the end of the closure phase since their MRM was never achieved simultaneously with the bite (Figure 5C, Table 2). 
Table 2 Mean $( \pm S D)$ of the kinematic variables studied for the different behaviors studied

\begin{tabular}{|c|c|c|c|c|}
\hline & $F A$ & FPF & $S P$ & $F P F^{*}$ \\
\hline$\# 1) \operatorname{MRM}\left({ }^{\circ}\right)$ & $8.7 \pm 0.5$ & $8.2 \pm 1.1$ & $14.1 \pm 3.3$ & $7.5 \pm 0.6$ \\
\hline \#2) Max. lower jaw depression $\left(^{\circ}\right)$ & $18 \pm 3.4$ & $15.2 \pm 1.8$ & $14.5 \pm 0.3$ & $15.2 \pm 4.1$ \\
\hline \#3) Mean closing speed of lower jaw $\left({ }^{\circ} \mathrm{s}^{-1}\right)$ & $2771 \pm 376$ & $1688 \pm 325$ & $3829 \pm 1202$ & $396 \pm 65$ \\
\hline \#4) Max. acceleration in $\mathrm{RM}\left(10^{3} \mathrm{os}^{-2}\right)$ & $1078 \pm 71$ & $580 \pm 42$ & $1602 \pm 531$ & $85 \pm 18$ \\
\hline \#5) Time between (\#1) and the bite (ms) & 0 & 0 & 0 & $19 \pm 9$ \\
\hline \#6) Synchronization between hyoid apparatus and lower jaw accelerations (ms) & $0.4 \pm 0.4$ & $1 \pm 1$ & $0.3 \pm 0.7$ & $17 \pm 9$ \\
\hline \#7) Lower jaw closing duration (ms) & $3 \pm 1$ & $4 \pm 0.2$ & $3 \pm 1$ & $39 \pm 2$ \\
\hline
\end{tabular}

The c-md ligament is cut in the group with $a^{*}$.

No longer being physically connected, the maximum accelerations of the hyoid bar and the lower jaws were not synchronized (Table 2). Consequently, no slam of the buccal jaw was observed, and the mouth-closing phase lasted $40 \pm 11 \mathrm{~ms}$ (Figure 5C; see Additional file 4).

\section{Statistical comparative analysis}

High positive values along PC1 (52.87\% of variance, eigenvalue: 3.70$)$ are associated with rapid acceleration in the RM (\#4), simultaneity between MRM and the bite (\#5), synchronization between lower jaw and hyoid apparatus movement (\#6) and oral jaw slam (\#3 and \#7) (Table 3). This corresponds to the kinematic patterns performed with intact c-md ligaments ( $F A, F P S$ and $S P$ ), all of which are isolated from the pattern observed after transection (Figure 6, Table 4). However, the acceleration in the RM is significantly higher in $S P$ than in $F P F$, which mainly explains why these two patterns differ along PC1 (Table 4). High positive values along PC2 (16.91\% of variance, eigenvalue: 1.18) correspond to greater lower jaw depression and smaller MRM. SP differs from $F A$ and $F P F$ along this axis mainly because of its higher MRM (Figure 6, Table 4).

\section{Bite rates}

Intact fish had a mean bite rate of $3.01 \pm 0.98 \mathrm{~min}^{-1}$ $(\mathrm{n}=8)$. The ANOVA revealed different bite rates among

Table 3 Component loading scores from the PCA performed on the kinematic dataset

\begin{tabular}{llc}
\hline & PC1 & PC2 \\
\hline Variance explained (\%) & 52.87 & 16.91 \\
Eigenvalues & 3.70 & 1.18 \\
\#1) MRM & 0.55 & $\mathbf{- 0 . 7 0}$ \\
\#2) Max. lower jaw depression & 0.07 & $\mathbf{0 . 6 8}$ \\
\#3) Mean closing speed of lower jaw & $\mathbf{0 . 7 6}$ & 0.13 \\
\#4) Max. acceleration in RM & $\mathbf{0 . 8 3}$ & -0.31 \\
\#5) Time between (\#1) and the bite & $\mathbf{- 0 . 8 2}$ & -0.16 \\
\#6) Synchronization between hyoid apparatus & $\mathbf{- 0 . 7 7}$ & -0.22 \\
and lower jaw & & -0.20 \\
7) Lower jaw closing duration & $\mathbf{- 0 . 9 2}$ & \\
\hline
\end{tabular}

Significant loadings ( $>0.6)$ are bolded. intact, severed and control fish $\left(\mathrm{F}_{2,15}=19.82 ; p<0.001\right)$. A significant decrease of $81 \%\left(0.59 \pm 0.71 \mathrm{~min}^{-1}\right)$ in the bite rate was observed in individuals with the c-md ligament ablated $(p<0.001)$ but no effect of anesthetic was observed $(p>0.05)$ (Figure 7). In half of the individuals, the decrease reached more than $90 \%$. These data are probably underestimated because the GoPro camera does not allow the differentiation between bites and bite attempts. Each time it seemed that there was contact between the head of the fish and the rock, a bite was counted. The decrease observed in severed fish could not be due to a lack of filamentous algae since normal bite rates were observed in intact fish on the same rocks.

\section{Electromyography}

Activation in the adductor mandibulae $\mathrm{A}_{2}$ is always detected either in feeding or sound production events ( $\mathrm{N}=2$; 40 EMGs recorded) (Additional file 5). The activation starts $9 \pm 7 \mathrm{~ms}$ before the bite and keeps on until $8 \pm 10 \mathrm{~ms}$ after (Figure 8). Activations of epaxial and sternohyoideus muscles $(\mathrm{N}=1$, six EMGs recorded) start almost at the same time $(16 \pm 13 \mathrm{~ms}$ vs $14 \pm 9 \mathrm{~ms}$ before the bite) (Figure 8). That is in accordance with the kinematic data since movements of the two structures start at $10 \pm 5 \mathrm{~ms}, 11 \pm 5 \mathrm{~ms}$ and $13 \pm 10 \mathrm{~ms}$ before the bite for $F A, F P S$ and $S P$ respectively. Epaxial and sternohyoideus muscles are activated during the entire closure phase and until $6 \pm 3$ and $9 \pm 8 \mathrm{~ms}$ after the bite, respectively (Figure 8 ).

\section{Discussion}

Stegastes rectifraenum produces aggressive sounds made up of one to several pulses. Sounds with the same physical characteristics were also clearly recorded during the biting of filamentous algae. Kinematic analysis showed both kinds of events are produced through the slamming of the oral jaws, while the transection of c-md ligaments makes fish unable to perform such patterns.

\section{Sounds in agonistic behavior and grazing}

The pulsed-sounds of $S$. rectifraenum are similar to those produced by other damselfishes during different 


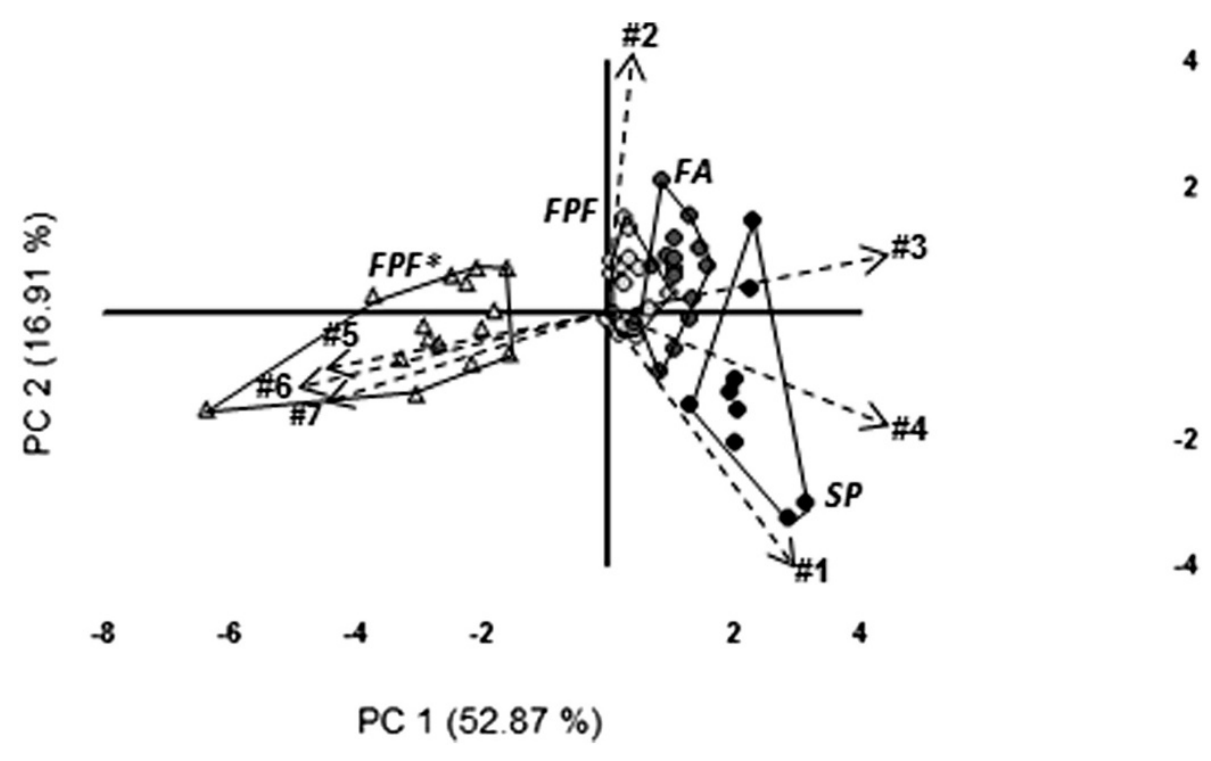

Figure 6 Plot of principal components 1 and 2 for all groups studied. The variables that load on each axis are indicated by the arrows, each arrow has a figure representing the variable: \#1) maximum relative distance (MRM) between the neurocranium and the hyoid apparatus; \#2) maximal lower jaw depression; \#3) mean closing speed of the lower jaw; \#4) maximum acceleration of relative separation between the neurocranium and hyoid apparatus; \#5) duration separating the time of the bite and the MRM between the neurocranium and hyoid apparatus; \#6) synchronization between the hyoid apparatus and mandible accelerations; \#7) mouth closing duration. The different kinds of behaviors are color and shape coded: black circles for sound production (SP), dark grey circles for biting filamentous algae (FA), light grey circles for biting fixed piece of food (FPF) and light grey triangles for biting fixed piece of food while the c-md ligament is ablated (FPF*).

agonistic interactions $[33,34,48]$. Similarities in dominant sound frequencies resulting from grazing and agonistic behaviors imply that the same basic underlying mechanism is used (i.e. the slam of oral jaws). On the other hand, variation observed in pulse durations could be related to other aspects of sound production, such as sonic radiation (see [47]). In all sequences of grazing studied with high-speed video, the individuals keep their jaws closed to pull away algae. This probably prolongs the vibration phenomenon of teeth collision. This is not the case in the sequences with sound production events where the mouth is directly reopened after the bite.

What is the role of the c-md ligament?

The three studied kinematic patterns (FA, FPF and $S P$ ) are all characterized by a slam of the oral jaws. In all of them, the movements of the neurocranium and the hyoid apparatus are first involved in mouth opening

Table 4 Statistical comparisons between the different behaviors studied along the two main PC factors and the kinematic variables

$F P F \neq F P F^{*} \quad S P \neq F P F^{*} \quad F A \neq F P F^{*} \quad F A \neq S P \quad S P \neq F P F \quad F A \neq F P F$

\begin{tabular}{|c|c|c|c|c|c|c|c|}
\hline & & $F P F \neq F P F^{*}$ & $S P \neq F P F^{*}$ & $F A \neq F P F^{*}$ & $F A \neq \mathrm{SP}$ & $S P \neq F P F$ & $F A \neq F P F$ \\
\hline & Anova results & & & & & & \\
\hline 2) Max. lower jaw depression & $F_{3,50}=1.58 ; p>0.05$ & & & & & & \\
\hline & Kruskal-Wallis results & & & & & & \\
\hline & $\mathrm{H}_{3,54}$ & & & & & & \\
\hline${ }^{\mathrm{C} 1}$ & $48.03 ;{ }^{*}$ & * & * & * & ns & * & ns \\
\hline $\mathrm{C} 2$ & 17.50 & ns & ns & * & * & * & ns \\
\hline 1) MRM & 24.74 & ns & * & ns & * & * & ns \\
\hline 3) Mean closing speed of lower jaw & $37 i^{*}$ & * & * & * & ns & ns & ns \\
\hline 4) Max. acceleration in RM & $44.62 ;{ }^{*}$ & * & * & * & ns & * & ns \\
\hline 5) Time between (1) and the bite & $42.67 ;^{*}$ & * & * & * & ns & ns & ns \\
\hline 6) Synchronization between hyoid apparatus and lower jaw & $18.52 i^{*}$ & * & * & * & ns & ns & ns \\
\hline 7) Lower jaw closing duration & $38.90 ;{ }^{*}$ & * & * & * & ns & ns & ns \\
\hline
\end{tabular}

Summary of ANOVAS/Kruskal-Wallis and Multiple comparisons of mean ranks post-hoc tests, significant $p$-value $(<0.05)$ are indicated by a * 


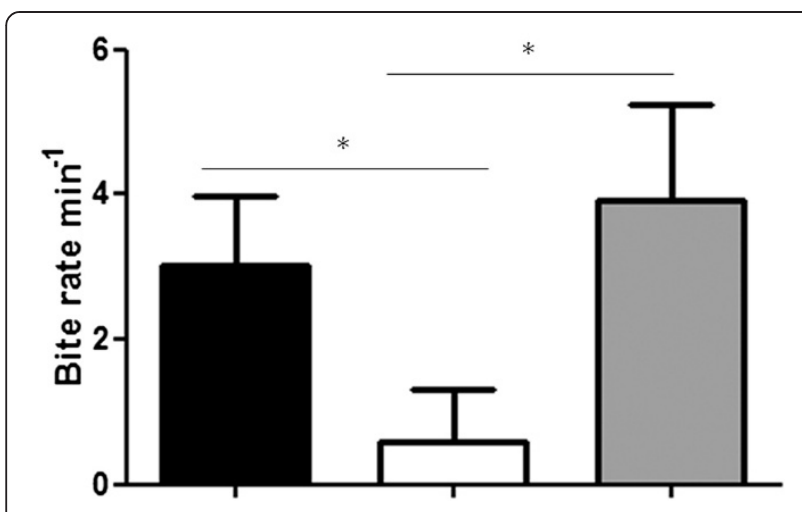

Figure 7 Bite rates on filamentous algae in Stegastes rectifraenum. Bite rates (mean $\pm \mathrm{SD}$ ) in individuals with the c-md ligament (in black), in individuals with this ligament ablated (in white) and in a control group (grey). Rates significantly different are indicated by $a$ *.

(phase 2) and then, thanks to the c-md ligament, they induce a slam of the oral jaws, closing the mouth in a few $\mathrm{ms}$ with an average speed that can reach more than $3000^{\circ} \mathrm{s}^{-1}$ (phase 3). In comparison, Labridae or Clariidae close their mouth at the speed of $673^{\circ} \mathrm{s}^{-1}$ and $1304^{\circ} \mathrm{s}^{-1}$, respectively $[49,50]$. The closure duration of $S$. rectifraenum is also shorter than in piscivorous fishes like Poeciliidae, Lepisosteidae, Belonidae or Sphyraenidae (2 to $4 \mathrm{~ms}$ vs 7 to $21 \mathrm{~ms}$; [51,52]), for which a strike success relies on jaws closure with high angular velocity and short duration.

The c-md ligament can close the mouth in a slam only if it is tightened quickly, and this depends on the speed in the relative movement between the neurocranium and the hyoid apparatus. Although a strong acceleration in this relative movement is observed in the three behaviors, some differences still exist. In sound production the

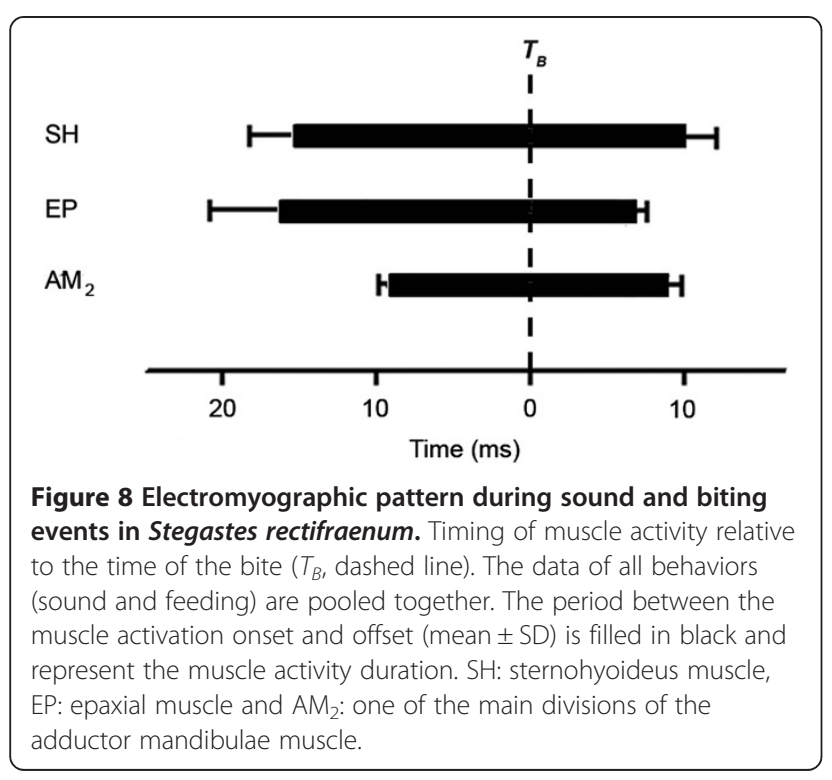

amplitude of the RM is higher than in both feeding behaviors and the acceleration in this movement is higher than in FPF. Thus the movement of $S P$ is exaggerated in comparison to the two others. We would expect these differences to result in a faster mouth closure, inducing stronger collision between teeth and a louder sound that would be useful to scare away an intruder or reinforce dominance. However our statistical tests do not reveal any differences in the average speed of mouth closure among the three behaviors (Table 4). This lack of a statistical difference may simply be a consequence of the limited temporal resolution in the videos because 500 fps may be too slow for this fast movement.

Without the c-md ligament, individuals close their mouth much more slowly. Unexpectedly, no acceleration in the RM was observed. It was expected that the individuals would try to perform the usual bite pattern and that only the oral jaw slam would not be present, but the entire pattern was affected. The results obtained through the bite rates experiment confirm that the c-md ligament is a key trait for grazing filamentous algae in $S$. rectifraenum. Indeed, the bite rates decrease by more than $80 \%$ in the severed fish (Figure 7); this rate dropped to almost zero in half of the fish tested. This assumption is reinforced by the fact that we were unable to record high-speed video data of filamentous algae bites from severed fish. Conversely, fish did not have difficulty in the seizure of FPF (no failure observed) and fed without hesitation on fixed piece of shrimp, even if the pattern performed was different (no oral jaw slam). That was the main reason why we studied biting on FPF in addition to grazing $F A$.

\section{What is the role of the adductor mandibulae?}

Although it is mechanically possible to both open and close the mouth by pulling along the working line of the epaxial and/or the sternohyoideus muscles, we showed that the $\mathrm{A}_{2}$ bundle works during the closing phase in all studied behaviors. Thus both systems (c-md ligament and adductor mandibulae) are acting in synergy during mouth closing. The c-md ligament confers speed advantage since it allows jaw slam, which cannot be performed with the adductor mandibulae alone. The adductor mandibulae cannot close the mouth so rapidly, but their action could allow a more powerful bite, inducing louder teeth collision or better algae seizure.

\section{Functional complexity mitigates functional trade-offs}

Functional trade-offs are thought to place strong constraints on the evolution of organismal performance [53-57]. A classic example is the trade-off between maximization of force and velocity in mouth closing systems often reported in fishes [50,58-62]. Grazing in damselfishes has to cope with two different mechanical 
demands: 1) the quick closing of the mouth on filamentous algae and 2) the development of enough force to extract the algae or to take undesirable objects out of the territory. The adductor mandibulae muscles, which are the main mechanism to close the mouth in teleosts [63], have evolved different functions in response to varying selection pressures. Manipulators that crush, scrape, excavate or tear their food have a more powerful forcegenerating capability of the adductor mandibulae. Conversely, the adductor mandibulae configuration of suction feeders allows for a better speed transmission to catch elusive prey $[64,65]$. More complex systems enable the mitigation of trade-offs [66]. For example, the force that a suction-feeding fish exerts on its prey can be enhanced by an expanded supraoccipital crest without a reduction in gape size which would decrease the spatial reach of the flow field [66]. The evolutionary bundle duplications of muscle clearly provide opportunity for increases in functional complexity [67]. In the majority of teleost fishes, the adductor mandibulae are divided into four main divisions: $A_{1}, A_{2}, A_{3}$ and $A_{\omega}$ [68]. In Labridae, the geometry of the $A_{3}$ muscles is better suited to fast closing, whereas the $A_{2}$ is designed for more forceful closing [69]. In Pomacentridae, in addition to these bundle duplications [46], the c-md ligament adds a new way to close the mouth, increasing even more the complexity of the system. Our kinematic study reveals that the c-md ligament confers a high-speed advantage in mouth closing. It could be expected that this releases some constraints on the adductor mandibulae, which evolution is modeled by the trade-off of speed-force transmission. Thus, an adductor mandibulae better suited for force transmission does not impede the ability of damselfish to close their mouth very quickly.

\section{Ecological implications of the c-md ligament}

Coral reefs harbor at least two ecological groups of fish that rely on algae as a main food source. First, roving grazers that feed in single or multi-species schools (primarily Acanthuridae, Scaridae and Siganidae) and second, grazers that are highly site-attached (primarily Pomacentridae and Blennidae). Grazing damselfishes defend small areas from conspecifics and all other herbivores [70] and are often referred to as farmers [22,26-29,45]. The farming of algal crops can be extensive or intensive. The intensive farming includes selective weeding of indigestible algae and prompt exclusion of herbivores; the extensive farming includes less prompt exclusion of herbivores and less weeding [29]. In both cases, the productivity and biomass of the farm is higher than that of the surrounding area [29].

We can also categorize herbivorous fishes according to their mechanics of feeding. Fishes such as scarids, which engulf large amounts of substrate per bite [17,71-74], or some acanthurids, which practice a heavy grazing on a larger surface like a lawnmower ([28,73]; pers. obs.), sometimes also ingest large amounts of sediment along with the algal filaments $[74,75]$. On the other hand, damselfishes are selective grazers, picking on small filamentous algae sometimes only a few $\mathrm{mm}$ long [26,45]. Bites of damselfishes are like surgical strikes that enable the fish to catch filamentous algae and prevent or decrease damage to the substratum supporting the crops. Accurate bites should also be useful for weeding out the undesirable algae without scraping the palatable filamentous algae. The very low fecal ash contents in the herbivorous damselfish species Stegastes dorsopunicans and S. planifrons [76] and the low amounts of sediment in the stomach contents of Pomacentrus wardi, Stegastes fasciolatus, S. fuscus, S. variabilis and Dischistodus perspicillatus [77-80] suggest highly selective feeding bites.

Though we need to study other farming species to confirm our results, we hypothesize that fast mouth closure is required to perform these accurate strikes efficiently. Indeed, the targeted filamentous algae are only a few $\mathrm{mm}$ long and slow mouth-closing movement would decrease success seizure because it would increase the probability the algae gliding along the lips. The other grazing species (e.g. blennids, acanthurids and scarids) engulf/scrape a large part of the substrate to ingest food of interest. This strategy is incompatible with farming because it would inevitably increase damages to the substrate supporting crops. This assumption is supported by the destruction of the farm by other herbivorous species once the resident pomacentrid is excluded $[25,27]$. The very fast mouth closing mechanism of damselfish possibly enables them to be highly selective and to perform accurate strikes on tiny filamentous algae, and probably allowed the evolution of such farming behavior.

\section{Conclusion}

We can assert the c-md ligament corresponds to a morphological novelty that obviously provides an innovation in the feeding mechanism allowing the use of resources in a different way. It allows accurate strikes on small filamentous algae by a slam of the oral jaw. This motion could be essential for the farming activity, an unusual behavior in teleost but that is practiced by many grazing damselfishes. Key innovations have been defined as attributes of organisms that potentially allow the taxon to occupy new niches and it seems that the c-md ligament fulfills this criterion. Moreover, the c-md ligament is also undeniably a key trait used for sound communication, a way of communication that is particularly well developed in damselfish. This suggests that the same character has been coopted for two different behaviors promoting the success of the family over evolutionary time in two ways: facilitating feeding and sound production. 


\section{Additional files}

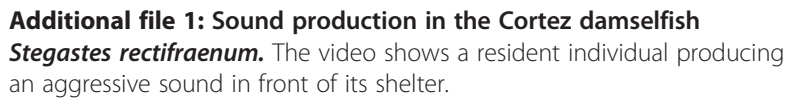

Additional file 2: Grazing in the Cortez damselfish Stegastes rectifraenum. The video shows the grazing activity of an individual on filamentous algae affixed to a rock. Generally, sound of teeth collision can be clearly heard during this behavior.

Additional file 3: High-speed videos of sound and biting events in feeding behaviors in the Cortez damselfish Stegastes rectifraenum.

The movie 1 corresponds to aggressive sound production (SP), the movie 2 corresponds to biting filamentous algae $(F A)$ and the movie 3

corresponds to biting fixed piece of food (FPF).

Additional file 4: High-speed videos of biting on fixed piece of food with and without the cerato-mandibular ligaments in the Cortez damselfish Stegastes rectifraenum. FPF correspond to a bite with the cerato-mandibular ligaments intact and FPF* correspond to the same situation but with the sectioned cerato-mandibular ligaments.

Additional file 5: Electromyographic pattern during grazing in the Cortez damselfish Stegastes rectifraenum. The sound produced by teeth collision and the activities of three muscles are indicated by colored-oscillograms. The muscular activities are adjusted with the onset of the sound (time of the bite).

\section{Competing interests}

The authors declare that they have no competing interests.

\section{Authors' contributions}

EP and BF designed the study. DO performed the experiments, analyzed the data and wrote the manuscript with contributions of EP and BF. EFB provides the infrastructures required for the experiments. MSZ caught the specimens used in this study. All authors read, revised and approved the final manuscript.

\section{Acknowledgements}

We thank Dr. Anthony Herrel for the 3-D reconstruction and Dr. Francesco Santini, Dr. Kelly Boyle and Dr. Célia Joaquim-Justo for linguistic assistance. Pablo Monsalvo and Gabriel Robles (CIBNOR) helped to maintain aquarium and fish conditions throughout the study. Enrique Calvillo helped in the caught of specimens. This research was supported by the FRFC grants from the F.R.S.-FNRS (no. 2.4.535.10) and project EPO.02 of CIBNOR. Damien Olivier is a PhD student of FRIA. Bruno Frédérich is a postdoctoral researcher at the FRS-FNRS.

\section{Author details}

'Laboratoire de Morphologie Fonctionnelle et Evolutive, AFFISH Research Center, Institut de Chimie (B6C) Université de Liège, B-4000 Liège, Belgium. ${ }^{2}$ Laboratorio de Fisiologia reproducion y cultivo de peces marinos, Centro de Investigaciones Biológicas del Noroeste, La Paz B.C.S. 23090, México. ${ }^{3}$ Laboratorio de Necton y Ecología de Arrecifes, y Colección Ictiológica, Centro de Investigaciones Biológicas del Noroeste, La Paz B.C.S. 23090, México.

Received: 13 June 2014 Accepted: 15 August 2014 Published: 22 August 2014

\section{References}

1. Baum DA, Larson A: Adaptation reviewed: a phylogenetic methodology for studying character macroevolution. Syst Zool 1991, 40:1-18.

2. Erwin DH: A preliminary classification of evolutionary radiations. Hist Biol: Internation J Paleobiol 2002, 6:133-147.

3. Heard SB, Hauser DL: Key evolutionary innovations and their ecological mechanisms. Hist Biol 1995, 10:151-173.

4. Levinton JS: Genetics, Paleontology, and Macroevolution. University Press: Cambridge; 1988.

5. Miller AH: Some ecologic and morphologic considerations in the evolution of higher taxonomic categories. In Ornithologie als Biologische
Wissenschaft. Edited by Mayr E, Sch Ÿz E. Heidelberg, Germany: Carl Winter; 1949:84-88.

6. Rosenzweigh ML, McCord RD: Incumbent replacement: evidence for longterm evolutionary progress. Paleobiology 1991, 17:202-213.

7. Van Valen LM: Adaptive zones and the orders of mammals. Evolution 1971, 25:420-428.

8. Haider M, Lindsey CC: Microvibrations in man and dolphin. Science 1964, 146:1181-1183.

9. Galis F: Key innovations and radiations. In The Character Concept in Evolutionary Biology. Edited by Wagner P. San Diego, CA: Academic Press; 2001:581-605.

10. Losos B: Adaptive radiation, ecological opportunity, and evolutionary determinism. Am Nat 2010, 175:623-639.

11. Liem KF: Evolutionary strategies and morphological innovations: cichlid pharyngeal jaws. Syst Zool 1973, 22:425-441.

12. Konow N, Bellwood DR: Prey-capture in Pomacanthus semicirculatus (Teleostei, Pomacanthidae): functional implications of intramandibular joints in marine angelfishes. J Exp Biol 2005, 208:1421-1433.

13. Konow N, Bellwood DR, Wainwright PC, Kerr AM: Evolution of novel jaw joints promote trophic diversity in coral reef fishes. Biol J Linn Soc 2008, 93:545-555.

14. Purcell SW, Bellwood DR: A functional analysis of food procurement in two surgenonfish species, Acanthurus nigrofuscus and Ctenochaetus striatus (Acanthuridae). Environ Biol Fish 1993, 37:139-159.

15. Streelman JT, Alfaro M, Westneat MW, Bellwood DR, Karl SA: Evolutionary history of the parrotfishes: biogeography, ecomorphology, and comparative diversity. Evolution 2002, 56:961-971.

16. Vial Cl, Ojeda FP: Cephalic anatomy of the herbivorous fish Girella laevifrons (Osteichthyes: Kyphosidae): mechanical considerations of its trophic function. Rev Chil Hist Nat 1990, 63:247-260.

17. Bellwood DR, Choat $\mathrm{JH}$ : A functional analysis of grazing in parrotfishes (family Scaridae): the ecological implications. Environ Biol Fish 1990, 28:189-214.

18. Autumn K, Sitti M, Liang YA, Peattie AM, Hansen WR, Sponberg S, Kenny TW, Fearing R, Israelachvili JN, Full RJ: Evidence for van der Waals adhesion in gecko setae. P Natl Acad Sci USA 2002, 99:12252-12256.

19. Hunter JP, Jernvall J: The hypocone as a key innovation in mammalian evolution. P Natl Acad Sci USA 1995, 92:10718-10722.

20. Bellwood DR, Wainwright PC: The history and biogeography of fishes on coral reefs. In Coral Reef Fishes: Dynamics and Diversity in a Complex Ecosystem. Edited by Sale PF. San Diego, CA: Academic Press; 2002:5-32.

21. Frédérich B, Sorenson L, Santini F, Graham JS, Alfaro ME: Iterative ecological radiation and convergence during the evolutionary history of damselfishes (Pomacentridae). Am Nat 2013, 181:94-113.

22. Ceccarelli DM: Modification of benthic communities by territorial damselfish: a multi-species comparison. Coral Reefs 2007, 26:853-866.

23. Choat JH: The Biology of Herbivorous Fishes on Coral Reefs. San Diego: The ecology of fishes on coral reefs Academic Press; 1991:120-155.

24. Hixon MA, Brostoff WN: Damselfish as keystone species in reverse: intermediate disturbance and divsersity of reef algae. Science 1983, 220:511-513.

25. Lobel PS: Herbivory by damselfishes and their role in coral reef community ecology. B Mar Sci 1980, 30:273-289.

26. Hata H, Kato M: Weeding by the herbivorous damselfish Stegastes nigricans in nearly monocultural algae farms. Mar Ecol-Prog Ser 2002, 237:227-231.

27. Hata $H$, Kato M: Demise of monocultural algal farms by exclusion of territorial damselfish. Mar Ecol-Prog Ser 2003, 263:159-167.

28. Vine PJ: Effects of algal grazing and aggressive behaviour of the fishes Pomacentrus lividus and Acanthurus sohal on coral-reef ecology. Mar Biol 1974, 24:131-136.

29. Hata H, Kato M: Monoculture and mixed-species algal farms on a coral reef are maintained through intensive and extensive management by damselfishes. J Exp Mar Biol Ecol 2004, 313:285-296.

30. Hata H, Watanabe K, Kato M: Geographic variation in the damselfish-red alga cultivation mutualism in the Indo-West Pacific. BMC Evol Biol 2010, 10:185.

31. Amorim MCP: Diversity of sound production in fish. In Communication in Fish. Edited by Ladich F, Collin SP, Moller P, Kapoor BG. Enfield: Science Publishers; 2006:71-105.

32. Colleye O, Parmentier E: Overview on the diversity of sounds produced by clownfish (Pomacentridae): importance of acoustic signals in their peculiar way of life. PLoS One 2012, 7:e49179. 
33. Mann DA, Lobel PS: Acoustic behavior of the damselfish Dascyllus albisella: behavioral and geographic variation. Environ Biol Fish 1998, 51:421-428

34. Parmentier E, Kéver L, Casadevall M, Lecchini D: Diversity and complexity in the acoustic behaviour of Dascyllus flavicaudus (Pomacentridae). Mar Biol 2010, 157:2317-2327

35. Parmentier E, Colleye $O$, Fine ML, Frederich B, Vandewalle $P$, Herrel A: Sound production in the clownfish Amphiprion clarkii. Science 2007, 316:1006.

36. Stiassny ML: The phyletic status of the family Cichlidae (pisces, perciformes): a comparative anatomical investigation. Neth J Zool 1981, 31:275-314.

37. Muller M: Optimization principles applied to the mechanism of neurocranium levation and mouth bottom depression in bony fishes (Halecostomi). J Theor Biol 1987, 126:343-368.

38. Ferry-Graham LA, Wainwright PC, Bellwood DR: Prey capture in long-jawed butterflyfishes (Chaetodontidae): the functional basis of novel feeding habits. J Exp Mar Biol Ecol 2001, 256:167-184.

39. Ferry-Graham LA, Wainwright PC, Hulsey CD, Bellwood DR: Evolution and mechanics of long jaws in butterflyfishes (family Chaetodontidae). J Morphol 2001, 248:120-143.

40. Ha SJ: Aspects of Sound Communication in the Damselfish Eupomacentrus partitus. USA: Unpublished Doctoral Dissertation, University of Miami; 1973.

41. Myrberg AA Jr: Underwater sound: its relevance to behavioural functions among fishes and marine mammals. Mar Freshw Behav Phys 1997, 29:3-21.

42. Myrberg AA Jr, Spanier E, Ha SJ: Temporal patterning in acoustic communication. Contrasts Behav 1978, 137-179.

43. Myrberg AA Jr, Spires JY: Sound discrimination by the bicolor damselfish, Eupomacentrus partitus. J Exp Biol 1972, 57:727-735.

44. Spanier E: Aspects of species recognition by sound in four species of damselfishes, genus Eupomacentrus (Pisces: Pomacentridae). Z Tierpsychol 1979, 51:301-316.

45. Montgomery WL: Comparative feeding ecology of two herbivorous damselfishes (Pomacentridae: Teleostei) from the gulf of california, Mexico. J Exp Mar Biol Ecol 1980, 47:9-24.

46. Gluckmann I, Bussers JC, Poulicek M, Vandewalle P: Preliminary study of the morphology of the head in Pomacentridae: adductor mandibulae organization in Dascyllus aruanus (Teleostei: Perciformes). Proc 5th Indo-Pac Fish Conf 1999, 89-97.

47. Colleye $\mathrm{O}$, Nakamura $\mathrm{M}$, Frédérich $\mathrm{B}$, Parmentier E: Further insight into the sound-producing mechanism of clownfishes: what structure is involved in sound radiation? J Exp Biol 2012, 215:2192-2202.

48. Colleye $\mathrm{O}$, Vandewalle $\mathrm{P}$, Lanterbecq D, Lecchini D, Parmentier E: Interspecific variation of calls in clownfishes: degree of similarity in closely related species. BMC Evol Biol 2011, 11:365

49. Ferry-Graham LA, Wainwright PC, Westneat MW, Bellwood DR: Mechanism of benthic prey capture in wrasses (Labridae). Mar Biol 2002, 141:819-830.

50. Van Wassenbergh S, Aerts P, Adriaens D, Herrel A: A dynamic model of mouth closing movements in clariid catfishes: the role of enlarged jaw adductors. J Theor Biol 2005, 234:49-65.

51. Ferry-Graham LA, Hernandez LP, Gibb AC, Pace C: Unsual kinematic and jaw morphology associated with piscivory in the poeciliid, Belonesox belizanus. Zoology 2010, 113:140-147.

52. Porter HT, Motta PJ: A comparison of strike and prey capture kinematics of three species of piscivorous fishes: Florida gar (Lepisosteus platyrhincus), redfin needlefish (Strongylura notata), and great barracuda (Sphyraena barracuda). Mar Biol 2004, 145:989-1000.

53. Bennett AF, Lenski RE: An experimental test of evolutionary trade-offs during temperature adaptation. P Natl Acad Sci USA 2007, 104:8649-8654

54. Futuyma DJ, Moreno G: The evolution of ecological specialization. Annu Rev Ecol Syst 1988, 19:207-233.

55. Khoel MAR: When does morphology matter? Annu Rev Ecol Syst 1996 27:501-542.

56. Wainwright PC, Carroll AM, Collar DC, Day SW, Higham TE, Holzmann R: Suction feeding mechanics, performance, and diversity in fishes. Integr Comp Biol 2007, 47:96-106

57. Walker JA: A general model of functional constraints on phenotypic evolution. Am Nat 2007, 170:681-689.

58. Collar DC, Near TJ, Wainwright PC: Comparative analysis of morphological diversity: does disparity accumulate at the same rate in two lineages of centrarchid fishes? Evolution 2005, 59:1783-1794.
59. Kammerer CF, Grande L, Westneat MW: Comparative and developmental functional morphology of the jaws of living and fossil gars (Actinopterygii: Lepisosteidae). J Morphol 2005, 267:1017-1031.

60. Turingan RG, Wainwright PC, Hensley DA: Interpopulation variation in prey use and feeding biomechanics in Carribean triggerfishes. Oecologia 1995, 102:296-304.

61. Westneat MW: Transmission of force and velocity in the feeding mechanisms of Labrid fishes (Teleostei, Perciformes). Zoomorphology 1994, 114:103-118.

62. Westneat MW: Evolution of levers and linkages in the feeding mechanisms of fishes. Integr Comp Biol 2004, 44:378-389.

63. Ferry-Graham LA, Lauder GV: Aquatic prey capture in ray-finned fishes: a century of progress and new directions. J Morphol 2001, 248:99-119.

64. Sonnefeld MJ, Turingan RG, Sloan TJ: Functional morphological drivers of feeding mode in marine teleost fishes. Adv Zool Bot 2014, 2:6-14.

65. Wainwright PC, Bellwood DR: Ecomorphology of feeding in coral reef fishes. In Coral Reef Fishes: Dynamics and Diversity in a Complex Ecosytem. Edited by Sale PF. San Diego, CA: Academic Press; 2002:33-55.

66. Holzmann R, Collar DC, Mehta RS, Wainwright PC: Functional complexity can mitigate performance trade-offs. Am Nat 2011, 177:e69-e83.

67. Friel JP, Wainwright PC: Evolution of motor patterns in Tetraodontiform fishes: does muscle duplication lead to functional diversification? Brain Behav Evolut 1998, 52:159-170.

68. Wu K, Shen S: Review of the teleostean adductor mandibulae and its significance to the systematic positions of the Polymixiiformes, Lampridiformes, and Triacanthoidei. Zoo/ Stud 2004, 43:712-736.

69. Westneat MW: A biomechanical model for analysis of muscle force, power output and lower jaw motion in fishes. J Theor Biol 2003, 223:269-281.

70. Ceccarelli DM, Jones GP, Mc Cook LJ: Foragers versus farmers: contrasting effects of two behavioural groups of herbivores on coral reefs. Oecologia 2005, 145:445-453.

71. Bruggemann JH, Begeman J, Bosma EM, Verburg P, Breeman AM: Foraging by the toplight parrotfish Sparisoma viride: Il: intake and assimilation of food, protein and energy. Mar Ecol-Progr Ser 1994, 106:57-71.

72. Clements KD, Bellwood DR: A comparison of the feeding mechanisms of two herbivorous labroid fishes, the temperate Odax pullus and the tropical Scarus rubroviolaceus. Aust J Mar Fresh Res 1988, 39:87-107.

73. Hixon MA: Effects of reef fishes on corals and algae. In Life and Death of Coral Reefs. New York: Chapman and Hall; 1997:230-248.

74. Russ GR, John ST: Diets, growth rates and secondary production of herbivorous coral reef fishes. Proc 6th Int Coral Reef Symp, Aust 1988, 2:37-43.

75. Hiatt RW, Strasburg DW: Ecological relationships of the fish fauna on coral reefs of the Marshall Islands. Ecol Monogr 1960, 30:65-127.

76. Cleveland A, Montgomery WL: Gut characteristics and assimilation efficiencies in two species of herbivorous damselfishes (Pomacentridae: Stegastes dorsopunicans and S. planifrons). Mar Biol 2003, 142:35-44.

77. Feitosa JLL, Concentino AM, Teixeira SF, Ferreira BP: Food resource use by two territorial damslefish (Pomacentridae: Stegastes) on South-Western Atlantic algal-dominated reefs. J Sea Res 2012, 70:42-49.

78. Ho CT, Kao SJ, Dai CF, Hsieh HL, Shiah FK, Jan RQ: Dietary separation between two blennies and the Pacific gregory in northern Taiwan: evidence from stomach content and stable isotope analyses. Mar Biol 2007, 151:729-736

79. Townsend KA, Tibbetts IR: The ecological significance of the combtoothed blenny in a coral reef ecosystem. J Fish Biol 2004, 65:77-90.

80. Wilson S, Bellwood DR: Cryptic dietary components of territorial damselfishes (Pomacentridae, Labroidei). Mar Ecol-Progr Ser 1997, 153:299-310.

doi:10.1186/s12983-014-0063-z

Cite this article as: Olivier et al.: The cerato-mandibular ligament: a key functional trait for grazing in damselfishes (Pomacentridae). Frontiers in Zoology 2014 11:63. 